Portland State University

PDXScholar

Engineering and Technology Management

Faculty Publications and Presentations

8-2005

\title{
Improving Time to Market Forecasts: A Comparison of Two Technology Forecasting Techniques for Predicting U.S. Fighter Jet Introductions From 1944 to 1982
}

Lane Inman

Portland State University

Timothy R. Anderson

Portland State University, tim.anderson@pdx.edu

Robert R. Harmon

Portland State University, harmonr@pdx.edu

Follow this and additional works at: https://pdxscholar.library.pdx.edu/etm_fac

Part of the Engineering Commons

Let us know how access to this document benefits you.

\section{Citation Details}

Inman, Lane; Anderson, Timothy R.; and Harmon, Robert R., "Improving Time to Market Forecasts: A Comparison of Two Technology Forecasting Techniques for Predicting U.S. Fighter Jet Introductions From 1944 to 1982" (2005). Engineering and Technology Management Faculty Publications and Presentations. 44.

https://pdxscholar.library.pdx.edu/etm_fac/44

This Article is brought to you for free and open access. It has been accepted for inclusion in Engineering and Technology Management Faculty Publications and Presentations by an authorized administrator of PDXScholar. Please contact us if we can make this document more accessible: pdxscholar@pdx.edu. 


\title{
Improving Time to Market Forecasts: A Comparison of Two Technology Forecasting Techniques for Predicting U.S. Fighter Jet Introductions from 1944 to 1982
}

\author{
Lane Inman ${ }^{1}$, Timothy R Anderson ${ }^{2}$, Robert Harmon ${ }^{2}$ \\ ${ }^{1}$ Veritas Software, Corp., USA \\ ${ }^{2}$ Department of Engineering and Technology Management, Portland State University, USA
}

\begin{abstract}
Since its origin in 2001, technology forecasting using data envelopment analysis (TFDEA) has been tested with a number of applications. This paper uses a previously published technology forecast comparison of U.S. fighter jets between the years 1944 and 1982 to compare TFDEA to basic regression. Both techniques use aircraft introduced between 1944 and 1960 to predict the first flights of those fighters introduced between 1960 and 1982. TFDEA was found to better predict the first flight dates than the forecast using regression. These results indicate that TFDEA may be a powerful new technique for predicting complex technological trends and time to market for new products.
\end{abstract}

\section{INTRODUCTION}

Technology forecasting using data envelopment analysis (TFDEA) was first introduced as a quantitative approach for technology forecasting in 2001 [4]. Since its PICMET '01 introduction, it has been applied to a variety of industries including enterprise database systems, microprocessors, hard disk drives, and portable flash storage [3,10].

This paper uses TFDEA to revisit a classic paper by Joseph Martino comparing two different technology forecasting techniques' ability to predict the date of the first flight for U.S. fighter aircraft from 1944 to 1982 [13]. The two techniques used in the original paper were a scoring model and a regression based approach. The scoring model requires more adjustment to fit within this scenario and is therefore relegated to future work. Using the same data set, the scenario is modified in this paper to provide a better comparison of fighter jet performance forecasts. This is done by dividing the dataset into two components in a manner analogous to a holdout sample in regression. TFDEA results are then compared to the results of the regression-based approach used by Martino in 1993.

\section{BACKGROUND}

Martino has emphasized that a forecast's validity should be judged in so far as it helps a decision maker to make a correct and timely decision [12]. Therefore, it is reasonable to build a model based on what is known and then evaluate it based upon future data. This gives rise to the scenario underlying this comparison.

For this paper, consider yourself to be in the position of a U.S. defense aviation analyst in 1960. In the midst of the Cold War and the era's military conflicts, fighter aircraft were undergoing rapid development and adapting to changing mission requirements. Assume that based upon a needs analysis, you had the specifications of the seven fighter aircraft to be developed over the next 22 years and needed to predict when these aircraft might be expected to conduct their first flights. Without modification, this could also be viewed from the competitive perspective of a Soviet military strategist attempting to predict when new U.S. aircraft with advanced technology may be faced.

Predicting a new product's release date can influence the project's overall cost and return on investment. It also is of strategic importance since early release may be associated with increased long-term profits. Predicting a new product's release date is important whether you are in the high technology industry or the defense industry and has been the subject of voluminous work. These issues are explored in greater detail in the NPD literature and influential works include $[5,6,14,19,20]$.

\section{REGRESSION-BASED MODEL AND RESULTS}

Regression is an accepted model for both time-based and causal-based technology forecasting [17]. Martino [13] credits Alexander and Nelson [1] for making the strong connection between regression and technology forecasting. Alexander and Nelson referred to this approach planar tradeoff surface, which makes apparent the interpretation of the model. To make this paper more approachable for a general reader unfamiliar with the variety of quantitative technology forecasting techniques, we will refer to this approach as a regression-based technology forecast.

We used the same regression model as Martino [13] in terms of independent variables but limited our data set to the 19 U.S. fighter jets with first flights prior to 1960. Martino's regression model used only four of the seventeen potential characteristics due to the limited number of aircraft (data points) and the high correlation between these characteristics (independent variables), which would have caused significant regression problems. The four independent variables were selected based on a combination of application expertise and stepwise regression.

As shown in Table I, the regression model was significant and consistent with those obtained by Martino using the full 26 fighter jet data set [13]. As would be expected, the results differ but the magnitude and signs of the coefficients are the same as shown in Table II. 
TABLE I

REGRESSION FIT STATISTICS

\begin{tabular}{|l|r|}
\hline $\mathrm{R}^{2}$ & 0.943220 \\
\hline Adjusted $\mathrm{R}^{2}$ & 0.926998 \\
\hline Standard Error & 3.178914 \\
\hline Observations & 19 \\
\hline
\end{tabular}

TABLE II

REGRESSION MODEL

\begin{tabular}{|l|c|c|c|c|}
\hline & Coeffs. & $\begin{array}{c}\text { Std. } \\
\text { Error }\end{array}$ & t Stat & P-value \\
\hline Intercept & 1937.44 & 2.42652 & 798.4 & $5.2 \mathrm{E}-34$ \\
\hline $\begin{array}{l}\text { Maximum Mach } \\
\text { number }\end{array}$ & 6.89407 & 1.81625 & 3.796 & 0.001967 \\
\hline $\begin{array}{l}\text { Mean flying hours } \\
\text { between failures }\end{array}$ & 4.02832 & 1.04935 & 3.839 & 0.001807 \\
\hline Payload (lbs.) & 0.00269 & 0.00100 & 2.698 & 0.017311 \\
\hline $\begin{array}{l}\text { Range of BVR } \\
\text { missiles (miles) }\end{array}$ & 0.34162 & 0.10310 & 3.313 & 0.005124 \\
\hline
\end{tabular}

\section{TFDEA-BASED MODEL AND RESULTS}

\section{A. Modeling Process}

The TFDEA approach is similar to that of other DEA approaches. Inman [10] provides a step-by-step process and the mathematical details for conducting a TFDEA. For the purpose of brevity, a conceptual level explanation is provided in section $\mathrm{C}$.

\section{B. Input-Output DEA Model of Fighter Jets}

The four independent variables used by Martino all represent "goods" in that higher performance specifications indicate better performance. Therefore they were designated as outputs in terms of a DEA model. There was no characteristic analogous to an input so a constant value of 1.0 was used to reflect each aircraft as being able to successfully fly.

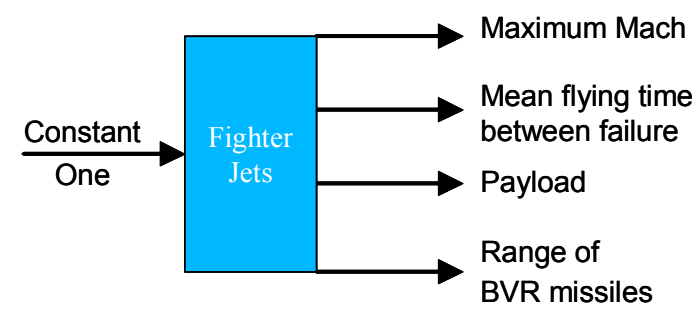

Figure 1. Basic input-output model of US fighter jets.

\section{Forecasting the Technological Rate of Change Using TFDEA}

TFDEA was used to estimate a rate of technology change from 1944 through 1959. Conceptually, this is done by using the first U.S. fighter jet, the F80, in 1944 to establish a technology frontier. The next jet, the F84, which first flew in 1946, is then compared against the 1944 frontier. If the new jet extends the efficiency frontier, the amount by which it extends the efficiency frontier is used to estimate a rate of technology change. Since two years have passed between the 1944 frontier and the 1946 frontier change caused by the F84, the annual rate of change estimate is the square root of the distance metric. If the F84 had not exceeded the technology frontier set by the F80, it would have been considered a noncompetitive product and that did not affect the rate of change estimate.

This process is repeated for each aircraft from the F86 in 1947 to the F5A in 1959 resulting in a series of annual rate of technology change estimates that can be used to forecast the first flight of future state of the art aircraft.

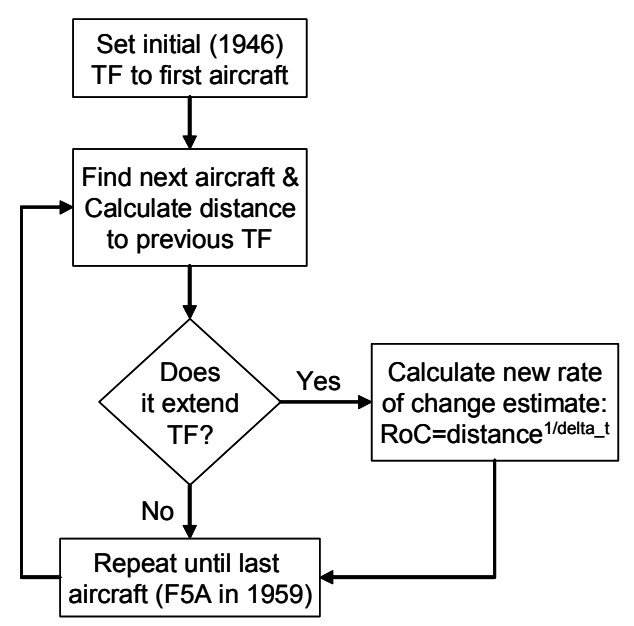

Figure 2. Process for Estimating Technological Rate of Change.

\section{Predicting the year of an aircraft's first flight}

This scenario posits the specifications of the upcoming seven planes (F4E, F14, F5E, F15, F16, F18, and F20) as being needed over the upcoming 22 years and attempts to predict their first flights. This is done by testing each of the 7 aircraft in each year to find out if their distance from the last efficiency frontier, 1959, is such that it would not have distorted technology frontier for that year, say 1963. A new technology frontier is implicitly found by comparing its distance to this from the 1959 technology frontier and if the distance is less than that predicted by raising the rate of change (RoC) to the fourth power. This process is summarized in Figure 3. 


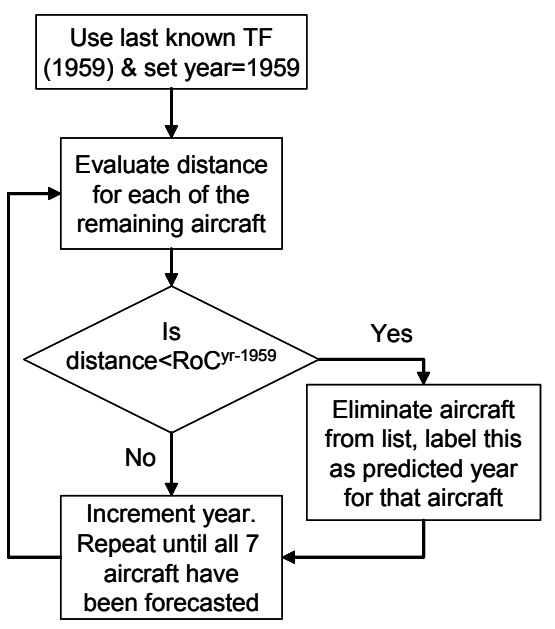

Figure 3. Process for Predicting Year of First Flight using TFDEA.

\section{COMPARISON OF TECHNOLOGY FORECASTS}

\section{B. Technology Forecasting Results}

Figure 4 provides a clear visual comparison of the technology forecasts. Aircraft falling on the diagonal line would have conducted their first flight at exactly the time predicted given their documented specifications. Aircraft lying above the line conducted their first flight earlier than the technology forecast(s) predicted. Aircraft falling below the line conducted their first flight later than the technology forecast predicted. From a new product development (NPD) perspective, these aircraft would represent underperforming products that were late to market.

Each of the 7 aircraft from 1960 to 1982 has two values falling on the same vertical line since the same actual plane had the same actual year of first flight. The diamonds in figure 4 represent the regression-based technology forecast of the year of the first flight for a particular plane. Similarly, the circles represent the TFDEA-based forecast.

This line can be interpreted as a plot of $Y$ vs. $\hat{Y}$ and the distances from this line can be interpreted as residuals. As would be expected, the regression-based forecasts are quite accurate for aircraft prior to 1960 since this data was used for building the regression forecast as well as the TFDEA forecast.

Two common methods of evaluating forecasts are by comparing the absolute deviations and the squared errors. Both methods give equal weight to errors of both underpredicting and over-predicting. The predicted release dates of the seven aircraft are given in Table III.

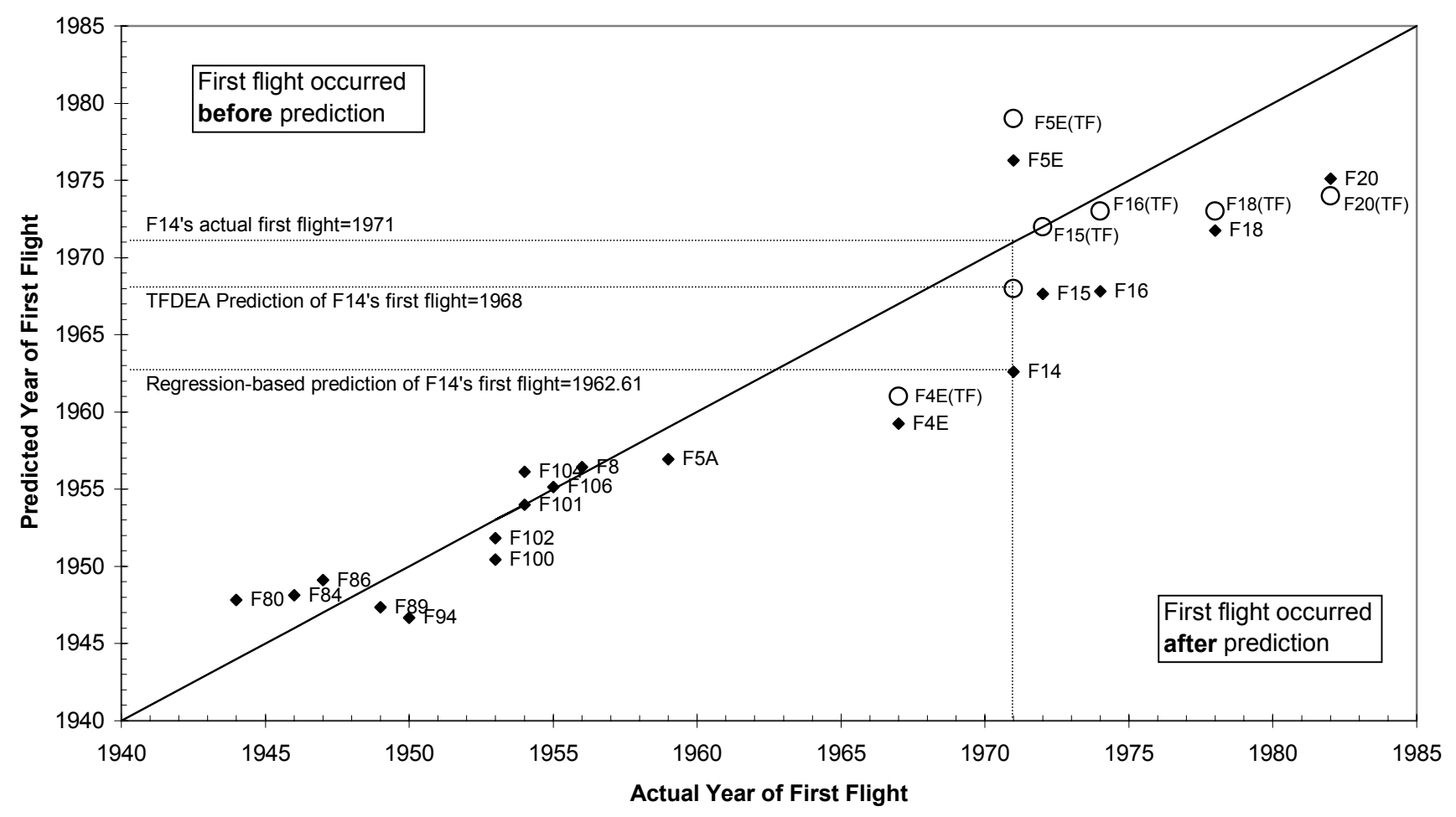

Figure 4. Predicted vs. Actual First Flights 
TABLE III

COMPARISON OF FORECASTED FIRST FLIGHTS FOR POST-1960 US FIGHTER JETS

\begin{tabular}{|c|c|c|c|c|c|c|c|}
\hline & & \multicolumn{3}{|c|}{ Regression-based Forecast } & \multicolumn{3}{c|}{ TFDEA-based Forecast } \\
\hline Aircraft & $\begin{array}{c}\text { Actual first } \\
\text { flight }\end{array}$ & $\begin{array}{c}\text { Predicted } \\
\text { first flight }\end{array}$ & $\begin{array}{c}\text { Absolute } \\
\text { deviation }\end{array}$ & $\begin{array}{c}\text { Squared } \\
\text { deviation }\end{array}$ & $\begin{array}{c}\text { Predicted } \\
\text { first flight }\end{array}$ & $\begin{array}{c}\text { Absolute } \\
\text { deviation }\end{array}$ & $\begin{array}{c}\text { Squared } \\
\text { deviation }\end{array}$ \\
\hline F4E & 1967 & 1959.25 & 7.75 & 60.10 & 1961 & 6 & 36 \\
\hline F14 & 1971 & 1962.61 & 8.39 & 70.43 & 1968 & 3 & 9 \\
\hline F5E & 1971 & 1976.31 & 5.31 & 28.17 & 1979 & 8 & 64 \\
\hline F15 & 1972 & 1967.64 & 4.36 & 19.04 & 1972 & 0 & 0 \\
\hline F16 & 1974 & 1967.82 & 6.18 & 38.15 & 1973 & 1 & 1 \\
\hline F18 & 1978 & 1971.75 & 6.25 & 39.05 & 1973 & 5 & 25 \\
\hline F20 & 1982 & 1975.10 & 6.90 & 47.55 & 1974 & 8 & 64 \\
\hline & & Means & $\mathbf{6 . 4 5}$ & $\mathbf{4 3 . 2 1}$ & & $\mathbf{4 . 4 3}$ & $\mathbf{2 8 . 4 3}$ \\
\hline
\end{tabular}

Having only seven aircraft instances in our sample limits the resolution of our statistical hypothesis testing, but we can still examine their significance with appropriate caveats. These results are summarized in Table IV. While there is evidence that TFDEA outperforms the regression-based technology forecast in this application, it must be interpreted carefully. The p-values are relatively high at $7 \%$ and $13.7 \%$ for the absolute deviation and squared deviation metric-based hypotheses respectively. These results would be considered weak when large sample datasets are used in more controlled statistical applications but given that we have a full population rather than a sample and the inherent challenges of technological forecasting, these are reasonably compelling.

TABLE IV

SIGNIFICANCE OF TECHNOLOGY FORECAST DIFFERENCES

\begin{tabular}{|l|c|c|}
\hline Hypotheses & t stat & $\mathrm{p}$-value \\
\hline$H_{0}: \mu_{\text {Regression }}^{\text {Absolute Deviation }}-\mu_{\text {TFDEA }}^{\text {Absolute Deviation }} \leq 0$ & & 0.070 \\
$H_{a}: \mu_{\text {Regression }}^{\text {Absolute Deviation }}-\mu_{\text {TFDEA }}^{\text {Absolute Deviation }}>0$ & 1.70 & $(7.0 \%)$ \\
\hline$H_{0}: \mu_{\text {Regression }}^{\text {Squared Deviation }}-\mu_{\text {TFDEA }}^{\text {Squared Deviation }} \leq 0$ & & \\
$H_{a}: \mu_{\text {Regression }}^{\text {Squared Deviation }}-\mu_{\text {TFDEA }}^{\text {Squared Deviation }}>0$ & 1.21 & 0.137 \\
\hline
\end{tabular}

\section{Discussion of results}

The deviations (or residuals) are consistent with those obtained by Martino [13] and the basic model of what is measured and what is not measured is the same as Martino's model. Therefore, his explanations and discussion regarding the reasons for residuals are equally valid for TFDEA.

For example, Martino noted that the F5E was released earlier than predicted using both his regression-based and scoring-based approaches. We also found the F5E to be released earlier than expected, and Martino's discussion applies equally well here. In particular, the F5E had the lowest range (120 miles) of any of the 26 planes, but since it was not included in the regression model, there was no "penalty" for its lower performance on this metric.
Martino concludes that the regression-based forecast and the scoring model provide similar quality of forecasts but that there are tradeoffs associated with them. For example, the scoring-based approach has a major advantage of being able to include a much larger number of characteristics than the regression-based approach. A significant disadvantage of the scoring-based approach is its reliance on an expert and the sensitivity of the results to their elicited weights. On the basis of examining the individual aircraft that suffered from poor predictions, he concluded with a slight preference for the scoring model's ability to incorporate more information.

TFDEA is built on an econometric technique, DEA, that is fundamentally different from regression and does not share regression's problems with multicollinearity [2]. Therefore, it is possible that more independent variables (inputs and outputs in DEA terminology) than the four selected by Martino could be used in this TFDEA study and thereby potentially recognizes problems such as the F5E's limited range. Like regression, DEA, and therefore TFDEA, requires a large number of observations (in this case aircraft) relative to the number of independent variables. While this might prevent us from enriching the model with some of the thirteen omitted aircraft characteristics, there are wellaccepted approaches to mitigate these problems in DEA by use of weight restrictions that could be used in TFDEA [10]. Martino's weights from the scoring-based approach could be potentially used as starting points in setting weight restrictions in the TFDEA model.

\section{Future Research}

TFDEA has potential to contribute to future research in three areas based on recent PICMET studies, These areas include the fuzzy front-end of NPD, evaluating NPD success, and technology roadmapping.

One challenge in the fuzzy front-end of NPD is setting realistic, marketable, and competitive design targets. Jetter [11] used fuzzy cognitive maps while Petersen and Yoder [15] used conjoint analysis. TFDEA would not supplant these techniques but could help test the the feasibility of targets based on the expected date of release. 
Many researchers have examined the factors that affect NPD success. Grant, et al, [9] examined the schedule delays in 22 weapon system development programs. Reilly, et al., [18] analyzed the impact of empowerment and its interaction with various sources of uncertainty in NPD and found that empowerment was associated with increased speed. However, measuring NPD speed is always a challenge since in some analyses it is compared against the original product proposal's release date. In cases where these release dates might be unrealistically optimistic to get a project funded, an alternative way of setting an expected release date may be useful. TFDEA could provide these alternate release dates and the residuals could then be viewed as another metric of schedule delay and NPD success (or the lack thereof). This would correspond to examining the reason why certain aircraft development projects fell in the lower right triangle of Figure 4.

Lastly, clarification between TFDEA, technology roadmapping and technology development envelope procedures can be explored. TFDEA is well-suited to setting NPD targets without specifying the particular technologies that required for a new product to deliver that performance. In 2002, Anderson et al. [3] used TFDEA to forecast microprocessor performance. One of the inputs used was power consumption. Achieving the desired level of performance could require significantly more power and therefore increased heat dissipation beyond the ability of current technologies. In 2003, Gerdsri and Kocaoglu [8] introduced TDE and applied it to electronic cooling technology in computer servers. The technology development envelope could then be used to help form a company's technology roadmap. Gerdsri further formalized TDE in recent work [7]. Phaal, et al., [16] provides a comprehensive introduction to technology roadmapping.

\section{CONCLUSION}

This comparison of technology forecasts was consistent with Martino's emphasis on the need for having a timely and beneficial impact on decision makers. The TFDEA results were statistically more accurate, and both methods only relied on data available to the hypothetical decision maker in 1960.

These preliminary results indicate that TFDEA may be a useful approach for predicting a product's date of release and thus provide an accurate estimate of time to market for complex new products. This information could then be used to assist in a variety of areas of NPD research.

\section{REFERENCES}

[1] A. J. Alexander and J. R. Nelson, "Measuring technological change: aircraft turbine engines," Technological Forecasting and Social Change, vol. 5, pp. 189-203, 1973.
[2] T. R. Anderson, "Data Envelopment Analysis," in Encyclopedia of Information Systems, vol. 1, H. Bidgoli, Ed.: Elsevier, 2003, pp. 445454.

[3] T. R. Anderson, S. Grosskopf, R. Fare, and X. Song, "Further examination of Moore's Law with data envelopment analysis," Technological Forecasting and Social Change, vol. 69, pp. 465-477, 2002.

[4] T. R. Anderson, K. Hollingsworth, and L. Inman, "Assessing the rate of change in the enterprise database system market over time using DEA," in Technology Management in the Knowledge Era, D. F. Kocaoglu and T. R. Anderson, Eds. Portland: PICMET, 2001, pp. 384-390.

[5] L. Bstieler, "The moderating effect of environmental uncertainty on new product development and time efficiency," Journal of Product Innovation Management, vol. 22, pp. 267-284, 2005.

[6] R. G. Cooper, Winning at New Products: Accelerating the Process from Idea to Launch, 3rd ed. Cambridge, Mass.: Persius Publishing, 2001.

[7] N. Gerdsri, "An analytical approach to building a technology development envelope (TDE) for roadmapping of emerging technologies," in Technology Management: A Unifying Discipline for Melting the Boundaries, D. F. Kocaoglu and T. R. Anderson, Eds. Portland: PICMET, 2005.

[8] N. Gerdsri and D. F. Kocaoglu, "An analytical approach to building a technology development envelope (TDE) for roadmapping of emerging technologies: A case study of emerging electronic cooling technologies for computer servers," in Technology Management for Reshaping the World, D. F. Kocaoglu and T. R. Anderson, Eds. Portland: PICMET, 2003, pp. 380-387.

[9] K. P. Grant, W. M. Cashman, and A. A. Omar, "Schedule delays in new product development: A life-cycle perspective," in Technology Management for Reshaping the World, D. F. Kocaoglu and T. R. Anderson, Eds. Portland: PICMET, 2003, pp. 290-297.

[10] L. Inman, "Technology Forecasting Using Data Envelopment Analysis," in Engineering and Technology Management. Portland: Portland State University, 2004.

[11] A. J. M. Jetter, "Educating the guess: Strategies, concepts and tools for the fuzzy front end of product development," in Technology Management for Reshaping the World, D. F. Kocaoglu and T. R. Anderson, Eds. Portland: PICMET, 2003, pp. 261-273.

[12] J. P. Martino, "Evaluating forecast validity," in A Guide to Practical Technological Forecasting, J. R. Bright and M. E. F. Schoeman, Eds. Englewood Hills: Prentice-Hall, 1984, pp. 26-52.

[13] J. P. Martino, "A comparison of two composite measures of technology," Technological Forecasting and Social Change, vol. 44, pp. 147-159, 1993.

[14] M. McGrath, Product Strategy for High Technology Companies: Accelerating Your Business to Web Speed. New York: McGraw-Hill, 2000.

[15] C. L. Petersen and L. Yoder, "Use of conjoint analysis and design of experiments in designing projection displays," presented at PICMET, Portland, 1999.

[16] R. Phaal, C. Farrukh, and D. Probert, "Developing a technology roadmapping system," in Technology Management: A Unifying Discipline for Melting the Boundaries, T. R. Anderson, D. F. Kocaoglu, and T. U. Daim, Eds. Portland: PICMET, 2005.

[17] A. L. Porter, A. T. Roper, T. W. Mason, F. A. Rossini, and J. Banks, Forecasting and Management of Technology. New York: John Wiley \& Sons, 1991.

[18] R. R. Reilly, J. Chen, and G. S. Lynn, "Power and empowerment: The role of top management support and team empowerment in new product development," in Technology Management for Reshaping the World, D. F. Kocaoglu and T. R. Anderson, Eds. Portland: PICMET, 2003, pp. 282-289.

[19] P. G. Smith and D. G. Reinertsen, Developing Products in Half the Time: New Rules, New Tools: Wiley, 1997.

[20] W. Zangwill, Lightening Strategies for Innovation: How the World's Best Firms Create New Products. New York: Lexington Books, 1993. 